\title{
أغراض خطابة الإمام الخميني و خصائص أسلوبها \\ محمد إقبال
}

\author{
خريج في قسم اللغة العربية كلية الآداب والعلوم الإنسانية جامعة الشريف هداية الله الإسلامية \\ الحكومية بجاكرتا
}

\begin{abstract}
Al-Khumayni is the first Iranian Supreme Leader had a big hand in the Iranian revolution. He was born on 24 September 1902 in Khomein, Markazi Province. Together with his followers in the city of Qum, al-AlKhumayni began to build a political base against the royal family especially the Shah of Iran Mohammed Reza Pahlavi, who later became an important part of the power steering Iran's Islamic Revolution. The main weapon held by al-Khumayni was political speeches capable of moving masses in large numbers so as to make future milestone Iranian empire felled. He was a great orator capable of sorting out the words and put them into a strand of pearls that evoke a spirit listeners to dissolve in their struggle against the Iranian royal family and American intervention. The style of language in his speech (Uslub Khithaby) which was the rhetorical speech trigger the urge author to analyze it more deeply through one of his speeches was phenomenal "American intervention in Iranian affairs".
\end{abstract}

Keywords: al-Khumayni, style of language, Kingdom of Iran, U.S. Intervention

\begin{abstract}
Abstrak
Al-Khumayni adalah Pemimpin Agung Iran pertama yang mempunyai andil besar dalam revolusi Iran. Beliau lahir pada tanggal 24 September 1902 di Khomein, Provinsi Markazi. Bersama pengikutnya di kota Qum, al-Al-Khumayni mulai membangun dasar politik untuk melawan keluarga kerajaan Iran khususnya Shah Mohammed Reza Pahlavi, yang kemudian menjadi bagian penting sebagai kekuatan pengarah Revolusi Islam Iran. Senjata utama yang dimiliki oleh al-Khumayni adalah pidato-pidato politiknya yang mampu menggerakan massa dalam jumlah besar sehingga membuat tonggak kerajaan Iran pada masa itu jatuh. Ia adalah seorang orator ulung yang mampu memilah kata dan menyusunnya menjadi untaian mutiara sehingga membangkitkan jiwa pendengar untuk larut dalam perjuangannya melawan keluarga kerajaan Iran dan intervensi Amerika. Gaya bahasa dalam pidato (Uslub Khithaby) al-Khumayni yang retorik memicu keinginan penulis untuk menganalisisnya lebih dalam melalui salah satu pidatonya yang fenomenal "Amerika intervensi urusan dalam negeri Iran”.
\end{abstract}

Kata Kunci: al-Khumayni, Gaya Bahasa, Kerajaan Iran, Intervensi Amerika 
والدينية، وشخصية الخطيب لها أثر فعال فلابد

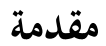
أن يكون بارعا في أداء أسلوبه متمرسا في معرفة نفوس السامعين حتى لا يثقل عليهم بكام محل فيملونه ويملون المتحدث. 3

فمن ذلك، كانت أسس الخطابة هي: مشافهة، وجمهور، وإقناع، واستمالة، ومن السهل بعد ذلك أن يتبين قصور تعريف الخطابة بأفها : فن الكلام الجيد، لأن الكلام الجيد ينتظم الخطابة والكتابة والشعر. كما هو معروف أن الإسلام منتشر في أنحاء العالم إنتشارا سريعا. وهذا لايخلو من كبار المسلمين الذين جاهدوا في إعلاء دين الإسلام، ومنهم الإمام الخميني في إيران.

إن الفروق بين الخطبة في عصر الجاهلية

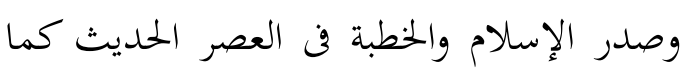
قد سبق بياها حثت الباحث على البحث في خصائص الخطابة في عصر الحديث من خلال خطبة الخمينيى تحت الموضوع "التدخل الأمريكي الشامل شؤون إيران الداخلية".

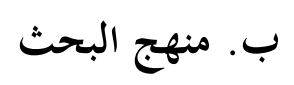

المنهج المستعمل في هذا البحث منهجا مكتبيا لأن المواد التي فيها نقلت من التأليفات التي تتعلق بها، وحول الباحث جمع

3نبيلة لوبس، المعين في الأدب العربي وتاريخه، (جاكرتا: كلية الأدب والعلوم الإنسانية جامعة شريف لإديف

أ. خلفية المشكلة

ينقسم تاريخ الأدب العربي إلى العصور

العديدة وهي : العصر الجاهلي والعصر الإسلامي والعصر الأموي والعصر العباسي وعصر الدول المتتابعة و والعصر الحديث. ولا لا لهري يبحث الباحث كل هذه العصور وإنما يقتصر على العصر الحديث يبتدئ بقيام الحركات الإصلاحية في بعض البلاد العربية كحركة الشيخ محمد بن الوهاب في شبه الجزيرة العربية في منتصف القرن الثاني الهجري كما يعد التأثير الأوروبى (سلبا أو إيجابا) في بداية القران الثالث عشر الهجرى أثر في بعض البلاد العربية كما هو الحال في سوريا و لبنان و مصر. 1

الخطابة قسم من أقسام النثر، والخطابة في زمن السابقة محتاجة إليها المسلمون للنشاط والنصيحة بنيهم. وينبغي على الخطيب أن يزيّن خطبتهم بما فيه من المحسنات اللفظية والمعنوية. الخطبة هي كلام جيد المعاني متين الأسلوب مؤثر في من يستمع إليه. 2 والفصاحة عماد

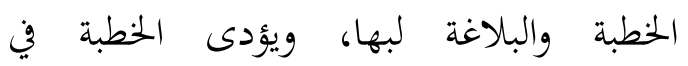
الإجتماعات السياسية و والفكرية والثعبية

$$
\begin{aligned}
& 1 \text { الدكور عبد العزيزبن محمد الفيصل، الأدب العربي }
\end{aligned}
$$

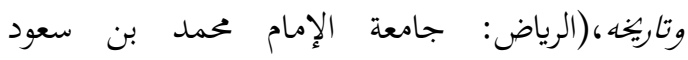

$$
\begin{aligned}
& \text { الإسلامية، ب · ع ()، ص } \\
& \text { 2الدكور عبد العزيزبن محمد الفيصل، الأدب العربي }
\end{aligned}
$$


دراسة على يد فقهاء مجتهلي عصره، اهتم بدراسة علم الرياضية الهيئة والفلسفة. وفي الوقت ذاته الذي اهتم بكسب العلوم، حرص على المشاركة في دروس اخلاق والعرفان، ودرس أعلى مستويات العرفان النظري والعلمي لدي المرحوم

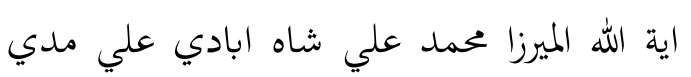
ست سنوات. بدأ الإمام الخميني الراحل بمزأولة

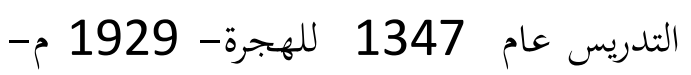
أي منذ سن السابعة والعشرين، إذا بدأ بتدريس الفلسفة الإسلامية وطوال فترة إقامته في مدينة قم، درس سماحته بحوث الفلسفة الإسلامية والعرفان النظري والفقه والأخلاق الإسلامية. 5 ب. بياته الاجتماعية

نشأ الإمام آية الله روح الله الخميني

ضمن عائلته المسلمة. وقد اغتيل والده وعمره آنذاك خمسة شهور إذاخترات له اسرته مرضعة لتعمل على ترتيبه. ثم التحق بالحوزة العلمية في سن مبكرة وبدأ من هناك حياته العلمية والعملية.

وبالنسبة للحالة الزوجية الإجتماعية

لروح الله الخميني، فقد تزوج بسن الخامسة والعشرين من فتاة إيرانية اسمها (خديجة بنت محمد الثقيفي) وانجبا عدة أبناء من بينهم : مصطفى (الذي اغتاله جهاز السافاك

5 لجنة التحرير، لمحات من حبات وجهاد الإمام

الخميني، ص. 6
المصادر والمراجع العربية التي تتكلم عن أغراض خطابة الإمام الخميني وخصائصها وأسلوبها.

الإمام الحميني

أ. مولده و نشأته ووفاته

ولد الإمام

1320للهجرة- 9/21 / 1902م- بمدينة

خمين-349كم جنوب غربي طهران- في بيت عرف بالعلم والفضل والتقوى. ولم تمض على ولادته ستة أشهر، حتى استشهد والده اية الله السيد مصطفى المستوى على أيدي الأشرار وقطاع الطرق المدعومين من قبل الحكومة وفتئذ. وكان استشهاده رحمه الله في الحادي عشر من ذى القعدة عام1320 للهجرة. وهكذا بترع الإمام الخميني منذ صباه مرارة اليتم وتعرف على الشهاد اشتغل الإمام في مدينة خمين حتى سن التاسعة عشرة بدراسة مقدمات العلوم بما فيها اللغة العربية والمنطق والأصول الفقه لدي أساتذة معروفين. وفي عام 1339 للهجرة 1921 م- الـ التحق بالحوزة العلمية في مدينة أراك. وبعد أن مكث فيها عاما، هاجر إلى مدينة قُم لمواصلة الدراسة في حوزةما. وهناك فضلا عن مواصلة 4لجنة التحرير، لمحات من حبات وجهاد الإمام الخميني، (طهران: مؤسس تنظيم ونشر تراث الإمام

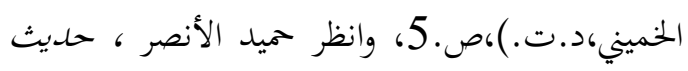
الانطلاق، (طهران: مؤسس تنظيم ونشر تراث الإمام

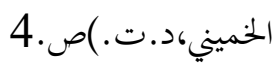


المقنعة المقرونة بالحجاج الدامغة الواضحة، ويكون ذلك بأسلوب مؤثر في المستمع بحسب المباج ما يقتضيه المقام. وتؤدى الخطبة في الإجتماعات السياسية والفكرية والشعبية والدينية.

من غاية الخطيب التأثير فن الارواح وامتلاك القلوب، لم يكفه في بلوغ هذه الغاية الاتيان بالأدلة فقط بل لابد له مع ذلك من التجمل

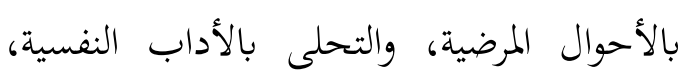
وبذلك يجذب إليه القلوب، ويستولى على لئى النفوس ويقودها إلى ما يريد منها وهي عشر صفات.

(الصفة الأول) سداد الرأي وإصالة العقل، وتمييزه لوجوه الأمور. (الصفة الثانية) صدق اللهخة وصحة القول، وحسن السيرة. (الصفة الثالثة) التودد إلى الناس، وموجبات التجبب

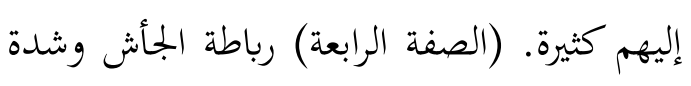
القلب. (الصفة الخامسة) البديهة الحاضرة،

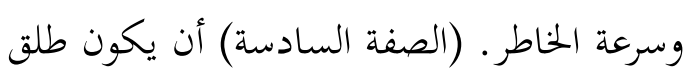

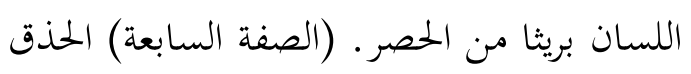
في إدراك مقتضي الحال وملاحظة طوائف الناس. (الصفة الثامنة) المهارة فن إثارة العواطف وتحريك الدرك أهواء النفوس. (الصفة التاسعة) سعة الإطلاع.

7 الشيخ علي محفوظ، الخطابة ، (المدينة المنورة : المكتبة العلمية، د. ت.)،ط4، ص صل 35
(المخابرات الإيرانية) واحمد من كبار مساعديه. وثلاث بنات هنّ : فريدة وصادفة وفاطمة. وجميعن تزوجن من علماء مسلمين من الشيعة. وقد نال الإمام آية الله الخميني شهرة إعلامية وسياسية ودينية عالمية واسعة، وبعد الثورة، وبعد قيام الجمهورية الإسلامية أواخر العقد الثامن من القرن العشرين، وجعلت بجلة (تايم) الأمريكية رجلا مشهورا، في عام 1979 وهو عام إنتصار الثورة الإسلامية الإيرانية على ظلم وطغيان شاة إيران الذي كان يلقب نفسه (شاهنشاه -ملك المملوكs).

\section{لمحة عن الحطابة والأسلوب}

عرف أن كلام العرب ينقسم إلى

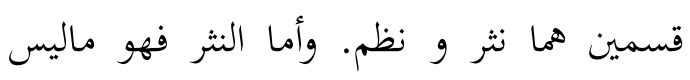
مرتبطا بوزن ولا قافية، والنظم هو الموزون المقفى. وفنون النثر متنوعة منها الخطابة وهي يرادبها الترغيب فيما ينفع وعما يضر، إلا أها تكون على ملأ من الناس في المجامع والمواسم. 6

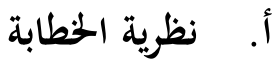

الخطابة نوع من النثر الفني الذى يؤثر فن النفس ويثير العواطف من طرق الطرح الأفكار

$$
\begin{aligned}
& 6 \text { أحمد حسين الزيات، تاريخ الأدب العربي للمدارس }
\end{aligned}
$$

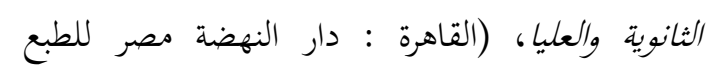

$$
\begin{aligned}
& \text { والنثر، د.ت.)ص } 18
\end{aligned}
$$


الناس تتكلم بلسان واحد فسرعان ما يختلفون في آرائهم ومعتقداقم بالصواب أوالخطأ، وإذا ذلك يتجادلون ويحأول بعضهم إقناع بعض ويتسابق النابهون منهم إلى استعمالة المخالف، وإلى التأثير فيه بشتى الطرق والضرب على أوتار فؤاده. نشأت الخطابة كفن الادبى قائم بذاته عندما كانت أهم وسيلة للاتصال بالجماهير وتوجيها، ولذالك اختلطت فن نشأها الأولى عند اليونان القدماء بفنون مختلفة من القول. فما يسميه أرسطو بالريطوريقا وهي لفظة ترجمها المترجمون السريان في العصر العباسى بلفظة الخطابة- لم تكن تعنى فن الخطابة كما تبلور فيما بعد، وإنما كانت تعنى فن البلاغة في القول على إطلاقه. 10

نشأة الخطابة العربية قديمة ترتبط بنشوء

الجماعات الأولى في البيئة العربية. فلا ريب أن العرب عرفوا الخطابة قبل الإسلام بزمن طويل.

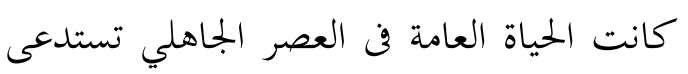
وجود هذا الفن. فالحياة القبيلة وما تستتبعه من منازعات وخصومات حروب، وما تؤدى اليه هذه الحروب أحيانا من محأولات لإصلاح ذات البين ونشر السلم بين القبائل المتنازعة، وإضطراب الحياة الدينية عند العرب قبل الإسلام ومارافق هذا الإضطراب من محأولات للارشاد والدعوة لنبذ عبادة الأوثان. والحياة السياسية في

10 محمد مندور، الأدب وفنونه، (القاهرة: دار النهضة

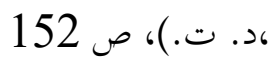

(الصفة العاشرة) التجمل شارته وإشارته وملابسه وهيئته وحب النظام في كل ما يختف بالخطبة. 8 وتنقسم الخطبة إلى أربعة أقسام : (1) المقدمة. لابد ان تكون جذابة مشرقة إلى أذهان السامعين متناسبة مع الخطبة. يجتنذب فيها انتباه السامعين، ويتجه بعقليتهم وجهة معينة وقد يتركها الخطيب إذا لم يجد داعيا اليها؛(2) الموضوع، و هو العنصرالأساسى وفيه يبسط الخطيب فكرته ويسرح وجهة نظره في ترتيب منطقى مقبول، فيبدأ عادة بالمألوف لينتقل إلى البعيد المجهول، وأن يكون عرضه للنتيجة التى يقصدها؛(3) البراهين. وهي رهينة بطبيعة الموضوع فيقدم الخطيب بعضها مؤيدا وجهة نظره مدلولا عليها، ويؤخر بعضها كى يفند حجح خصمه، ويجب على الخطيب أن يكون مقتنعا بصواب وجهة نظره وخطأ مخالفه؛(4) الخاتمة و فيها يجمع الخطيب أطراف الموضوع ويترك في أذهان السامعين صورة واضحة موجزة لما يتنأوله في الخطبة مجتذبا عواطف السامعين إلى رأيه، وأن تكون قصيرة ما امكن، وقد يتركها الخطيب أحيانا.

\section{ب. نشأة الخطابة وتطورها}

فن الخطابة قديم وجد مع الإنسان ونشأ بنشأته وارتقى برقيه، فمتى وجدت جماعة من

$$
8 \text { 8 الشيخ علي محفوظ، الخطابة،ط4، ص 36-38 }
$$
9 أشرف محمد موسى ، الخطابة وفن الإلقاء، (القاهرة:

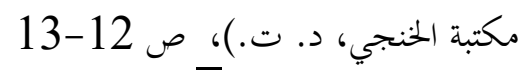


يكشف فيه مؤامرة العدوان الثلاثي التي دبرتا

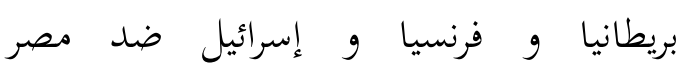

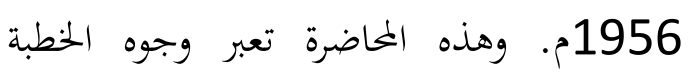
السياسة في العصر الحاضر من هذه المرحلة.

والخطابة السياسة وهدفها اقناع

المسلمين برأى سياسى يستحسن الناس به الحكم

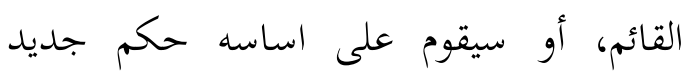
والشئون العامة للدولة كفى البرلمان المجتمعات

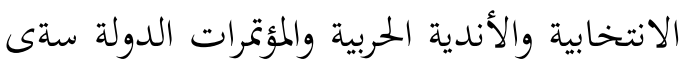

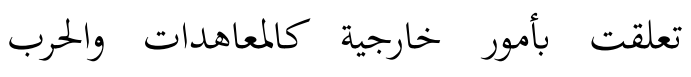
والسلاح، أو بأمور داخلية كالتعليم والإقتصاد والزراعة والتشريع ونظم الحكم. أو بأمر داخلية كالعا.

أما خطب المدح والندوات الأدبية فمعظمها قيلت في الحفلات التى تقام لتكريم

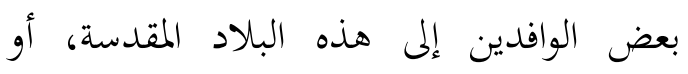

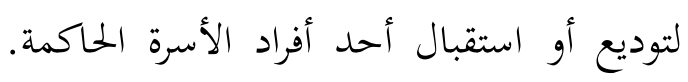

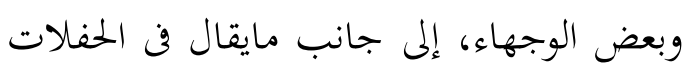

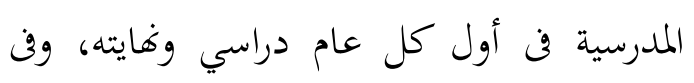

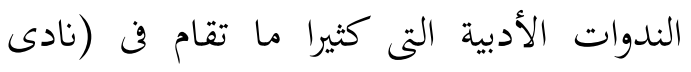

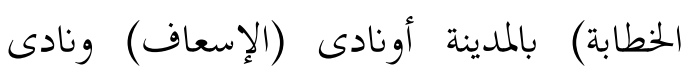

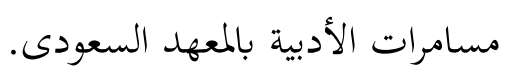

والخطب الإجتماعية للتعليم دوره العظيم

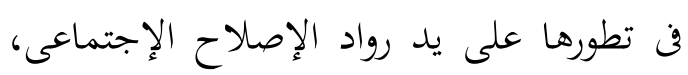

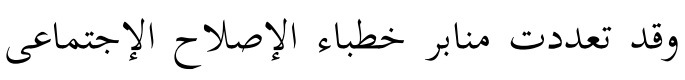
مما اسرع فن دفع عجلة وتطور سكان هذا الإقليم وعلى مستوى الأفراد. وإذا كان التعليم هو المؤثر
ذلك العصر وما كانت تفرضه على العرب من

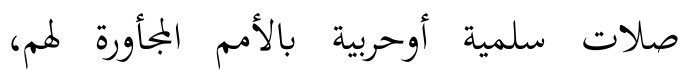

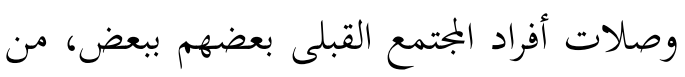
تزأوج وتعامل وتنافر وتفاخر وما فطر عليه العرب من فصاحة ولسان وحضور بديهة، كل أولئك أمور كانت تستدعى عن معرفة العرب الجاهليين بالخطابة. 11

كان ظهور الإسلام إيذانا بتطور واسع لئط في الخطابة منذ أن اتخذها الرسول الله صلى الله عليه وسلم أداة للدعوة إلى الدين طوال حياته. فكان يخطب في الناس داعيا كما عليه ربه " أدع لمعاته إلى سبيل ربك بالحكمة والموعظة الحسنة" فأيقظ بخطبه الضمائر وقوى بكلامه. ت. حالة الحطابة في عصر الحديث في هذه المرحلة فقد تأثرت تأثيرا مباثرا

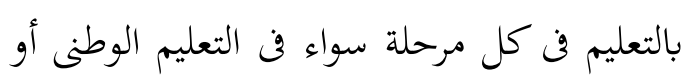
الخارجى عن طريق بعثات إلى الجامعات العربية

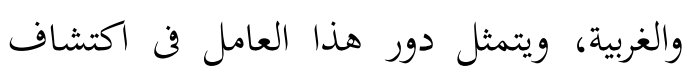

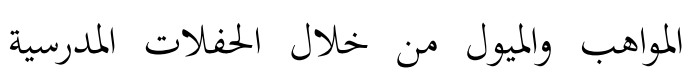

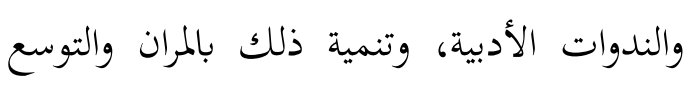
بالثقافة حسب مراحل التعليم، كما يضاف إلى الى ذلك جمال عبد الناصر في مصر من الخطبة الخبل

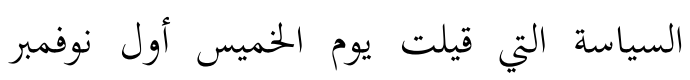

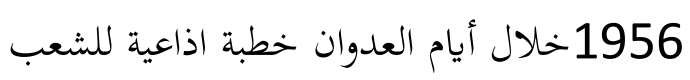

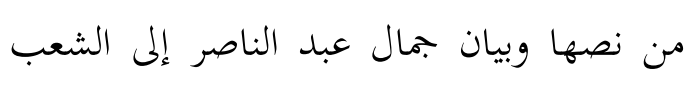
11 إحسان النص، الخطابة في عصرها الذهبي ( دار المعارف بمصر، د.ت.) ، ص 7-8 
5. الخطابة الإجتماعية، فهى تنأول الخطب

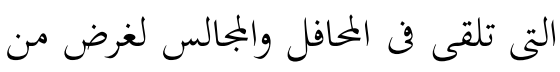
الأغراض المتصلة بالحياة الإجتماعية كالتهنئة والتعزية. 6. الخطابة القضائية، وهى المرافعات التى

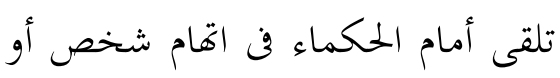

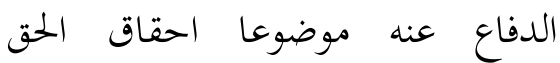
وابطال الباطل وبالفصل فيما ينشأ بين الناس من نزع.

\section{ج. أغراض الخطبة}

1. أغراض الحطابة فى العصر الجاهلي

$$
\text { 1) للمنافرات والمفاخرات }
$$

والمباهاة بقوة العصبية وكرم النجار، وشرف الحصال وعظم الفعال، ترهيبا لطامعين، وتهديدا للمعادين. 2) للتحريض على القتال والحض على لى لمدينان الأخذ بالثأر.

$$
\text { 3) لإصلاح ذات البين عند نثوب }
$$$$
\text { القتال. - القال. }
$$

4) للوعظ والتأمل والتوجيه.

$$
\text { 5) للوصيا }
$$

2. أغراض الحطابة في عصر صدر الإسلام: 1) (1) دعوة الناس إلى الايمان.

13 13 أممد محمد الخوفي ، فن الخطابة ، (القاهرة : دار النهضة، 1997م)، ص 72
المباشر في تطور الخطابة فإن الندوات الأدبية الثقافة العامة وغير هما من العوامل التى قد ساهمت في تطورها.

ث. ثنواع الحطابة واغراضها قد قسم الدكتور عبد العزيز بن محمد الفيصل إلى أقسام أربعة، وهي الخطابة الدينية والخطابة السياسة وخطابة الوفود و خطابة الحرب إنس

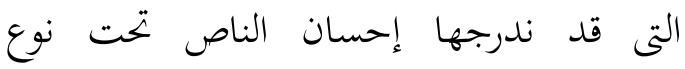
12

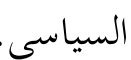

1. الخطابة الدينية وهى تشمل خطب

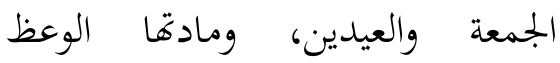

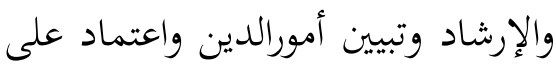

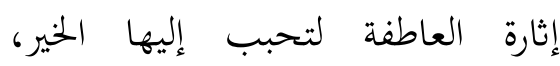
وتنفرها من الشر، وتوججها إلى تقوى

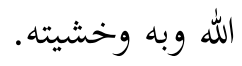

2. الخطابة السياسة وهدفها اقناع المسلمين وخينه برأى سياسى يستحسن الناس به الحكم

$$
\text { القائم. }
$$

3. الخطابة الوفود التى تفد على الخليفة إما

$$
\text { لتهنئة أو لتعزية أو تأييد سياسى. }
$$

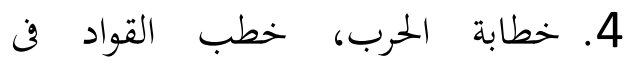

جيوشهم وتمدف هذه الخطابة إلى الى الى القاب

$$
\text { تحميس الجند للقتال. }
$$

12 عبد العزيزبن محمد الفيصل، الأدب العربي

وتاريخه،(المكتبة العربية : : وزارة التعليم العإلى العيلى

1405، مار)، ص 317 
قال على الجارم ومصطفى أمين بإن الأسلوب ينقسم إلى ثلاثة أقسام: 17

أ. الأسلوب العلمى، هو الأسلوب الذى أكثرها أحيانا إلى المنطق السليم والفكر الفرل

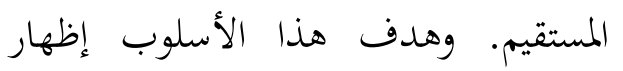
الحقيقة وتحليتها للسامع والقارئ، تمتاز هذا الأسلوب بالوضوح والحقة والتحيد والترتيب

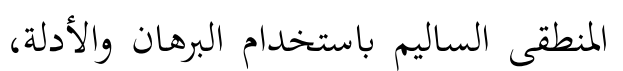
والبعيد عن التأنق والمبالغة. ب. الأسلوب الأدبي، هو الجمال أبرز صفاته ولتهانئه

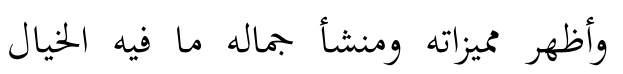
لرائع، وتصوير دقيق وتلمس بوجوه التشبيه البعيدة بين الأشياء إلباس المعنوى ثوب دوبل 18 المحسوس وإظهار في صورة المعنوى. ت. الأسلوب الخطابي، هو الأسلوب الذى تبرز

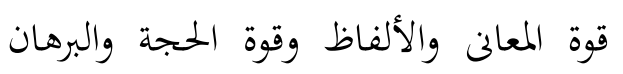

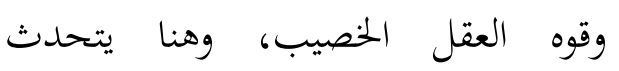
الخطيب إلى إرادة سامعية لإثارة عزائمهم

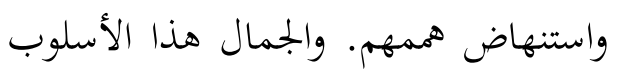
وضوحة شان كبير فن تأثيره ووصوله إلى همان هدان

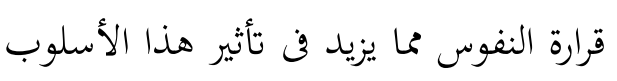
مترلة الخطيب في نفوس سامعية وقوة

17 على الجارم ومصطفى أمين، البلاغة الوضحة، (لبنان

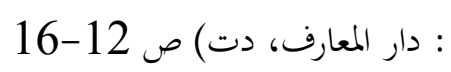
18 نفس المرجع، ص. 43
2) الحث على الجهاد والإستشهاد في

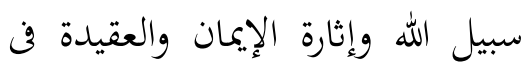

$$
\text { 3) خطابة السياسة }
$$

4) كان الخطابة جزأ من العبادة. كخطبة

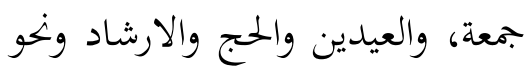

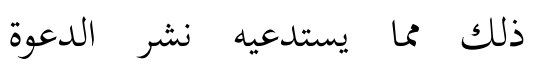
الإسلامية 14

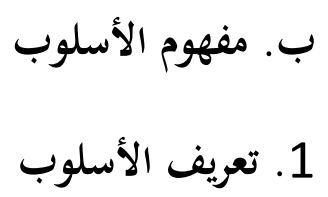

إن كلمة الأسلوب جمعها الأساليب، ومعناها لغة الطريقة أو الفن من القول. 15

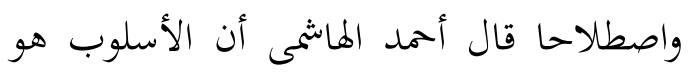

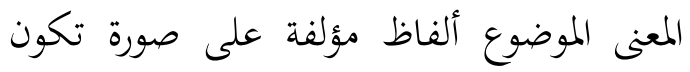
أقرب لنيل الغرض المقصود من الكلام وأفعل فن نفوس سامعية. 16

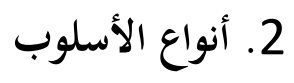
16 أممد الهاشي، جواهر البلاغة، (بيروت : دارالفكر، 
المعنى تبعا. 25 ومنها الإقتباس هو أن يتضمن

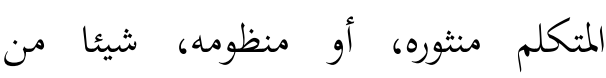

القرآن، أو الحديث، على وجه لا يشعر بأنه منهما. 26

الإنشاء الطلبى هو ما يستدعى مطلوبا غير حاصل وقت الطلب. 27 و أقسامه :

أ. النداء هو أعلم أن أغلب البيانين لم 28

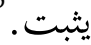

ب. فعل الأمر هو طلب حصول الفعل من

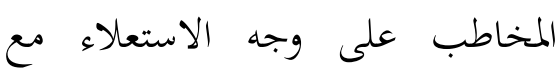

الإلزام.

ج. الإستفهام هو طلب العلم بشئ لم يكن معلوما من قبل.

الخبر هو كلام يحتمل الصدق أو الكذب لذا ته.$$
\text { خطبة الإمام الحميني }
$$

25 ـ أحمد الهانمي، جواهر البلاغة فى المعانى و البيان و

البديع، ص. آل آن

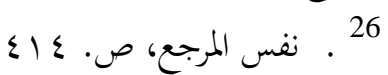

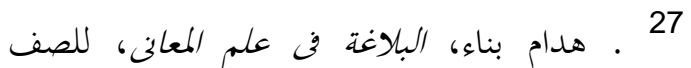

$$
\text { الخامس، ص بأن أحل }
$$

28 ـ أحمد الهاشمى، جواهر البلاغة في المعانى و البيان

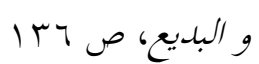

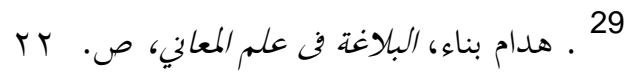

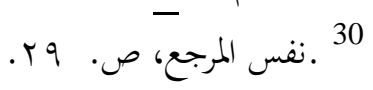

عارضته ووضوخ حجته ونبرات وصوته

وحسن إلقائه، ومحكم إشارته. 19

وتندرج في الأسلوب عدة العناصر البالغية وهي:

1) المحسنات المعنوية هى ما كان التحسين بها

راجعا إلى المعنى مع وضوح دلالته على المراد

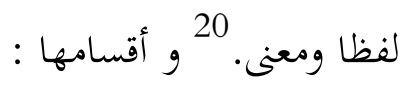

أ. الطباق هو أن الجمع بين الشئ

21 وضده.

ب. اللتغريق هو أن يفرق بين أمرين من نوع واحد في اختلاف حكومها. 22

ج. الجمع هو أن يجمع المتكلم بين متعدد،

تحت حكم واحد. 23

د. الأسلوب الحكيم هو تلقى المخاطب

بغير ما يترقبه إما بترك سؤله والإجابة

$$
\text { عن السؤال لم يسأله. }
$$

المحسنات اللفظية هى ما كان التحسين بها

راجعا إلى اللفظ بالاصالة، وإن حسنت

$$
19 \text { نفس المرجع،ص. } 16
$$

20 ـ أحمد الهاشمي، جواهر البلاغة فى المعانى و البيان و

$$
\text { البلديع، ص • بrr- البrr. }
$$

21

22 أحمد الهاشمي، جواهر البلاغة في المعانى و البيان و.

البديع، ص 377

23 نفس المرجع، ص. 377

24 نفس المرجع، ص. 388 
ينظروا أيّ من هذه المجالس يحق فيها للشعب أن

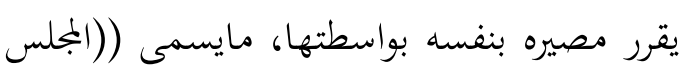
الوطني)) وبجلس ((الشيوخ))، ليأتوا وينظروا،

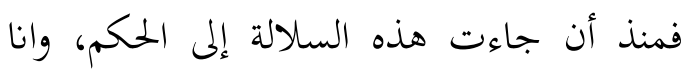

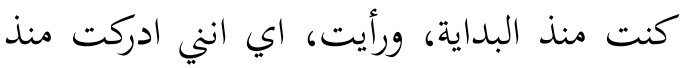

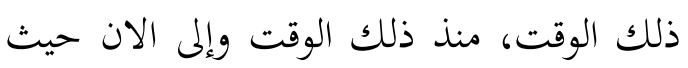
نزن الان هنا هؤلاء النواب-ايضا- يعملون في

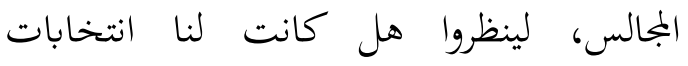

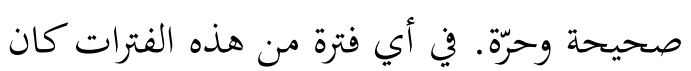

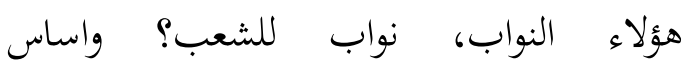
الديمقراطية هو أن يكون الشعب حراء فن ارائه.

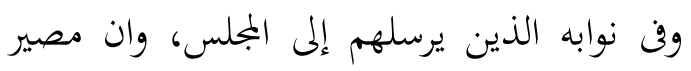

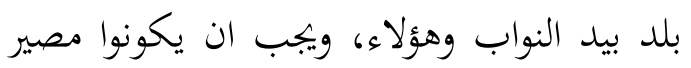

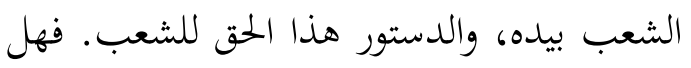
أن هذه الديمقراطية الشديدة ((الشدة والحزامة))

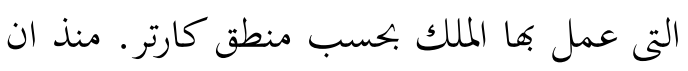

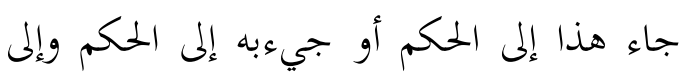

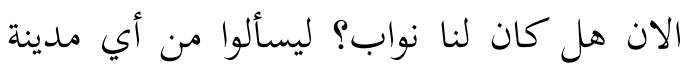
من مدن إيران شاءوا. هذه ليست قضية

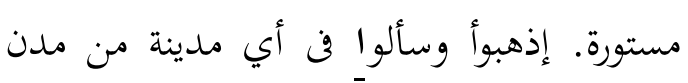

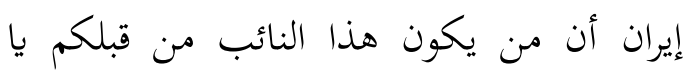
سيدى؟ أي إنسان هو؟ أن أكثر الناس لايعرفون هؤلاء بالأساس!!!ولا يعرفون من هم هؤلاء.

مدينة واحدة ! ليأتي هؤلاء ويقولوا

المدينة الفلانية. حسنا ليكون مركز طهران، ليأتوا

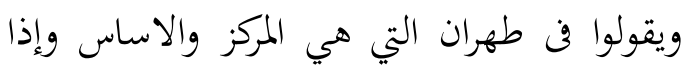
كان مقررا ان تكون هنا حرية ما يجب ان تكون

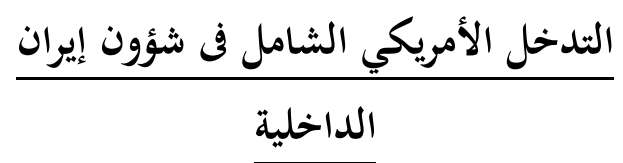

الديمقراطية الشديدة. . . أن هذا المعنى

أدى إلى أن يبدأ اليسار واليمين معارضتهما.

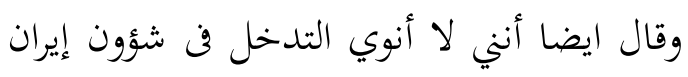

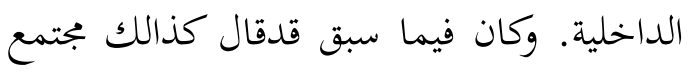

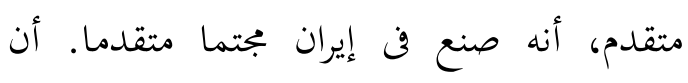

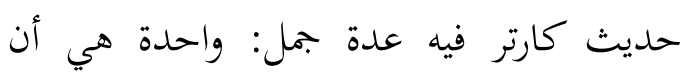

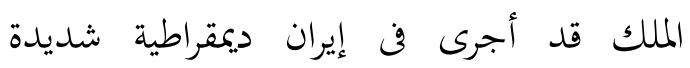
وحازمة ! هذه جملة واحدة. وبملة أن الملك قد إيكان

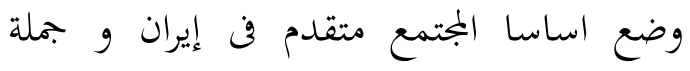

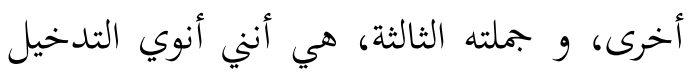

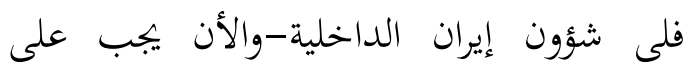

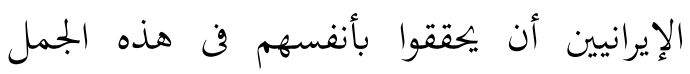
الثلاثة التي تحدث بها. ليروا ما إذا كانت موجهة الإنها

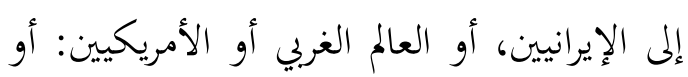

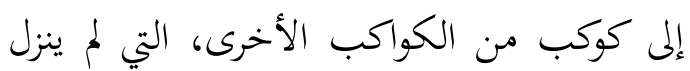

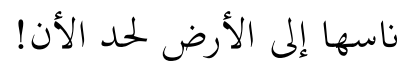
طيب، أن الجملة الأولى - الأن-هي أن

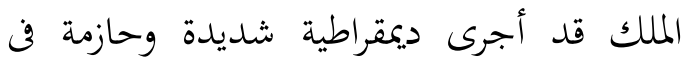
إيران ! أن أوضاع إيران، منذ ان فتحرئح الملك عيناه (على الدنيا) منذ أن كان في القماط وفتح عيناه

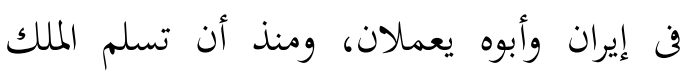

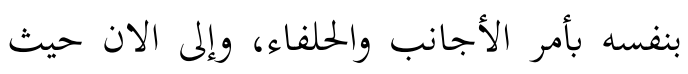

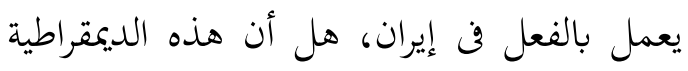

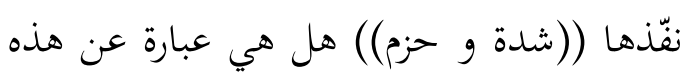

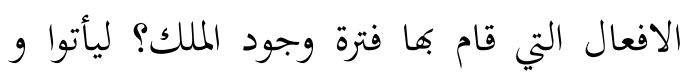


الأشياء.حسنا،كيف كانت قبل ذلك بعام؟ يتضح (من ذلك) أنه لم تكن هناك هذا الحرية فئ ذاك قبل عام من ذلك وهو قد منحها الأن. إذن أنه

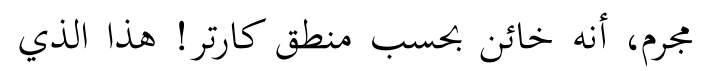

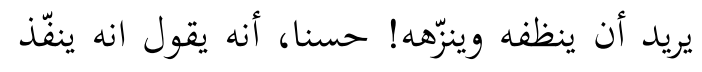

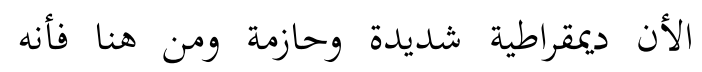
يختلف معه. حسنا، أن هذه الديمقراطية الشديدة

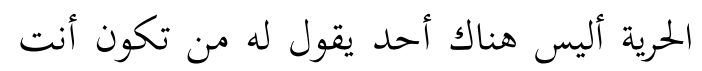

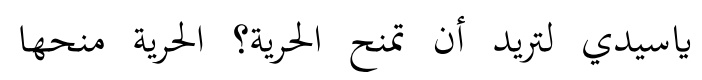

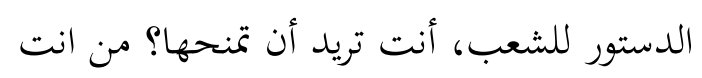

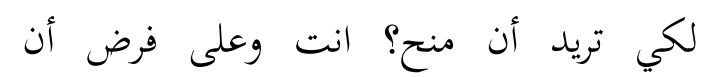
سلطنتك كانت سلطنة قانونية، في حين أها

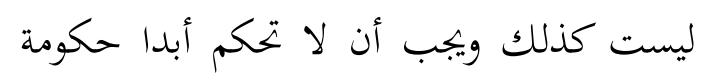

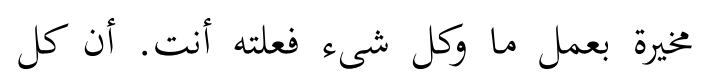
الجرائم تقع تبعا تما على عاتقك.

حسنا، فأن واحدا من هذه الأشياء الأعلامية هو الأذاعة والتلفزيون، فأي من هذين هذهان الأنياء المركزين استطاع إلى ان ينطق بكلمة، إذا عمل

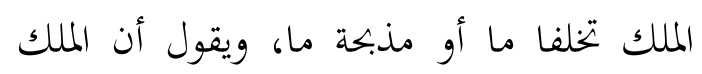
فعل هذا؟ أي من الصحف تجرأ الان على القول

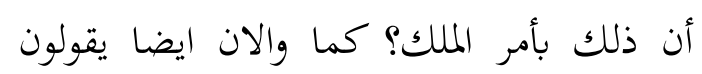

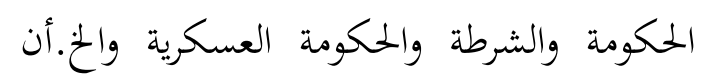

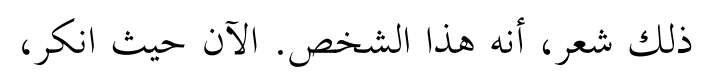

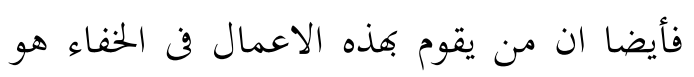
هذا الشخص، وإلاّ فما يهم الشرطة يكون الشعب في مكان هكذا.
في طهران التي هي مركز الساسة وامثالمم على

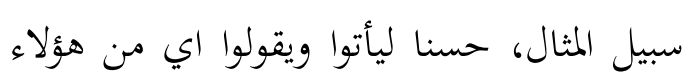

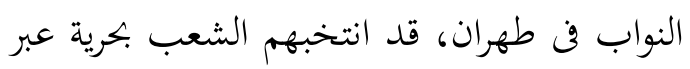

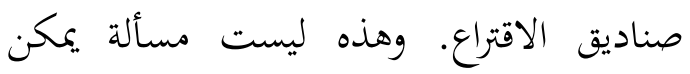

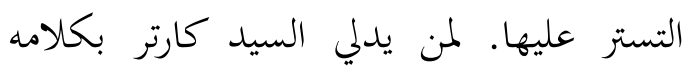

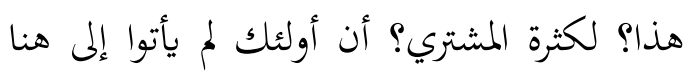

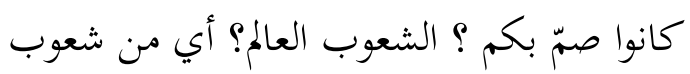
العالم لا يعرف هذا المعنى ؟ أيّ من صحافة العالم

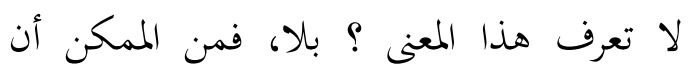
تكتب الكثير من الصحف لصالح السيد كارتر

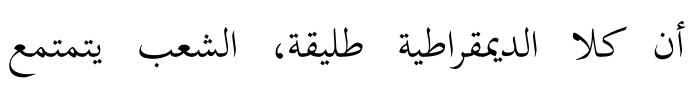

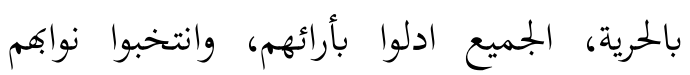

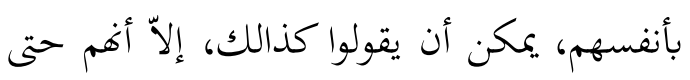

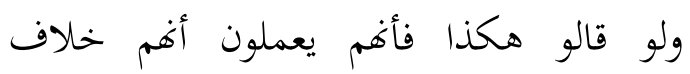

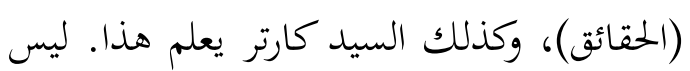
كارتر لا يعلم، يعلم أي انسان هذا. يعلم بنفسه أنسان

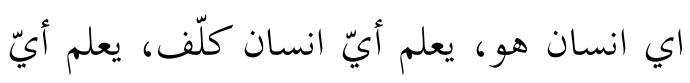

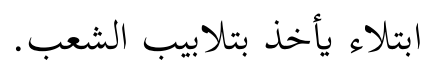

هذا بشأن قضية مستّمة هي من اركان الحرية بين الناس واعرض لكم هي الديمقرطية.

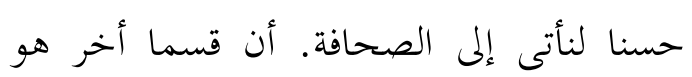

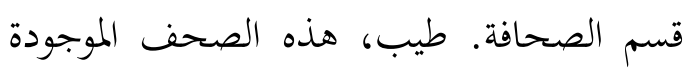

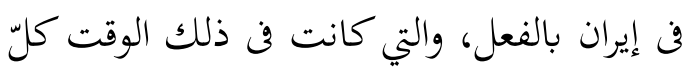
ما تكتبه لا نخرج عن اقوال ((صاحب الجلالة الاريا مهر)) وكل ما كانت تقوله لا يعد كونه

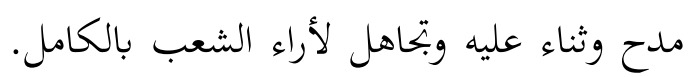

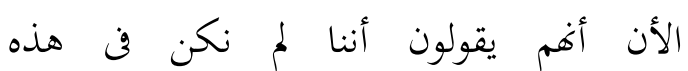


ايضا هو هذا المعنى! ففي منطق كارتر

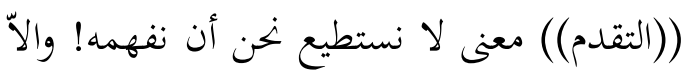

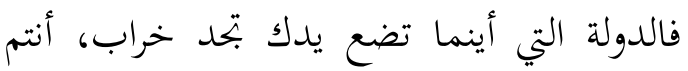

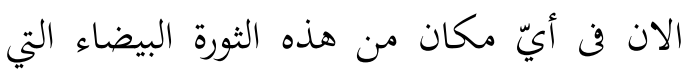

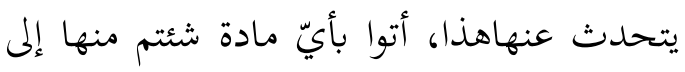
الججتمعات الإنسانية ولتنظروا ماذا فعل هذا بهذه

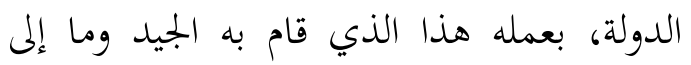
ذلك،فتلك القضية التي لم يعد فيها أرباب

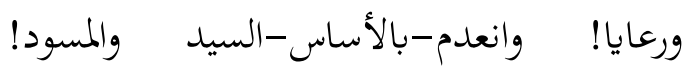

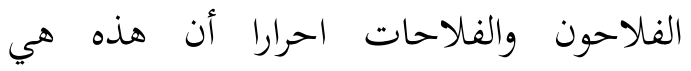
الكلمات التي كان يرددها باستمرار في ذلك الوقت. طيب، أن هؤلاء الفلاحين وهؤلاء

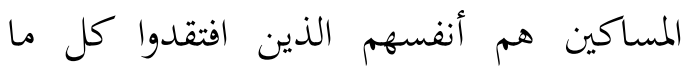

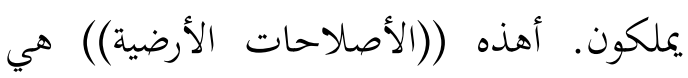

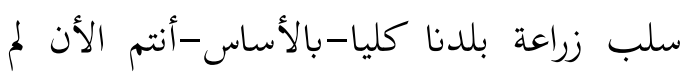
تعودوا تملكون زراعة في بلدكم.

أن الجميع الأعمال التي قام بها هذا

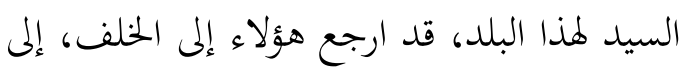

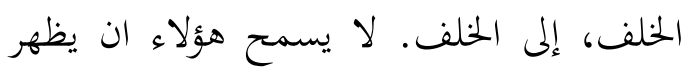
في بلدنا شخص مؤهل. أن هؤلاء يخشون من هولاء ان بطري

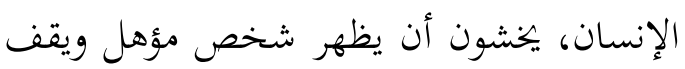

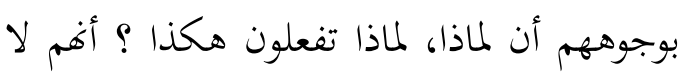

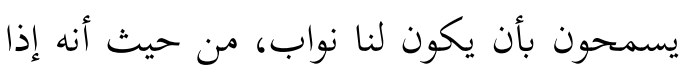
ما امتلكنا نواب، سيقفون بوجهرم ويسائلوفم

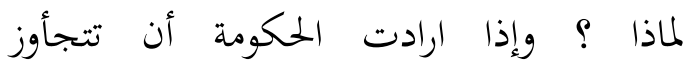

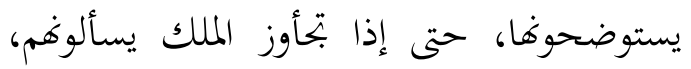
يعترضون عليه، ويستوضحون منه، أفم يعترضون
في أي حريّة يمتلك الشعب هذا الأعلام. فن هذا الأعلام الذي يقول أنه اعطى

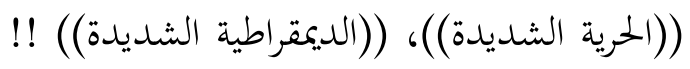

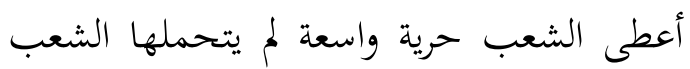
وأخذ يصيح! لأها ((شديدة)) جدا! وأن اليسار يعترضان على الملك الأن! وأن خلافهم هو أنه إنها! وان اليطار

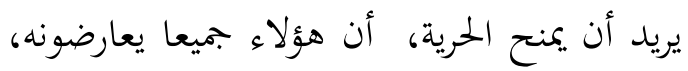
لا يريدون...! أن هذه الاستغاثات والهتافات التي هتف بها الجماهير في الشوارع (من قبيل):

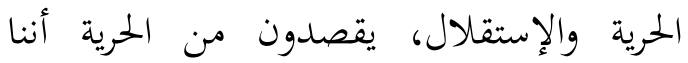
لانريد الحرية! أن الحرية والإستقلال تغنيان اننا لا

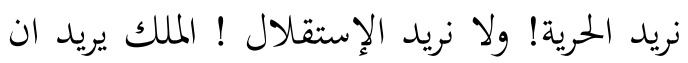

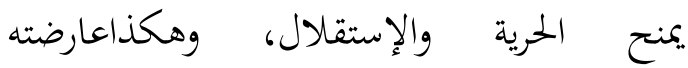
الجماهير!أن منشأ هذا التعبير- منشأ التعبير

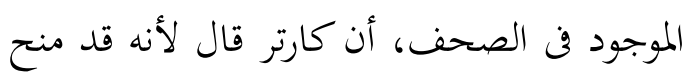

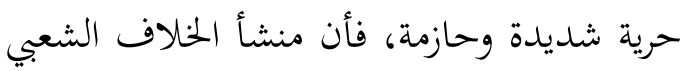

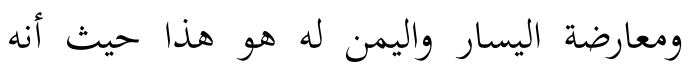

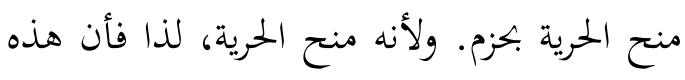

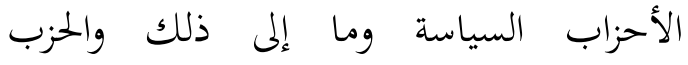
والكذائي ومختلف الجبهات تعارضه أن لماذا منحت الحريات!! والشعب ايضا يعارضه أن لماذا سمحت بالحريات!!هذا هو منطق كارتر بشأن

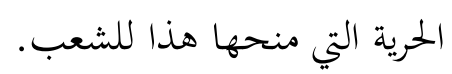
وأما ((الدولة المتقدمة)) حيث أنه بنى

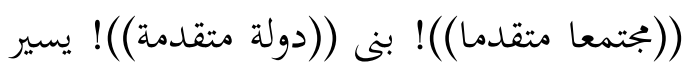

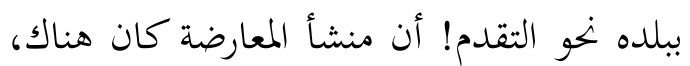

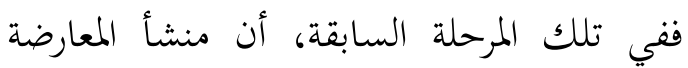


على وضع بلده، ويعرفون مالذى أجروه ويجرونه

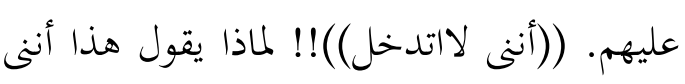

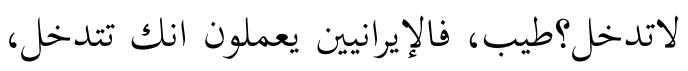

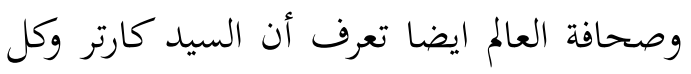

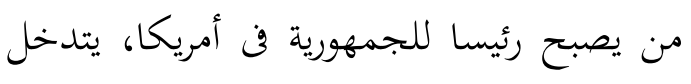

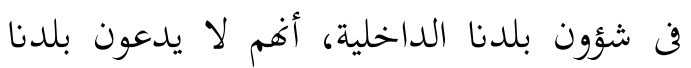

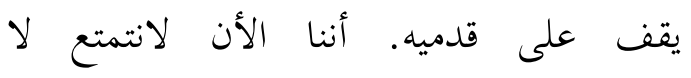
بالإستقلال ولا بالحرية، ولا الناس يتمتعون

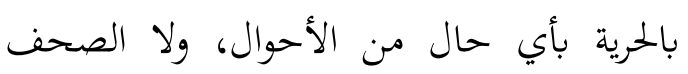

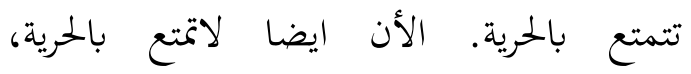

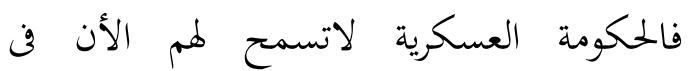
يتحدثوا. وهذه الصحف التي تدعي الأن أغا

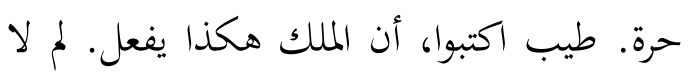
تكتبون؟ فلوبكثتم في جميع الصحف، فلا بتحدون هذه الكلمة وهي أن الذي يرتكب هذه الجرائم هوعبارة عن شخص الملك. أن هذه الجرائم كانت منذ البداية ولازالت ترتكب إلى الأن. ففي اليوم الذي ينهار فيه هذا لهاب الصرح

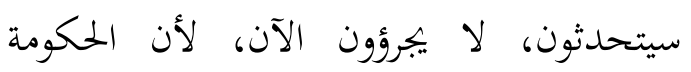

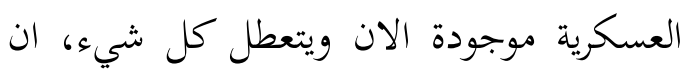
هؤلاء يغلفوها إذا تحدثت بمثل هذا الكلام أفم الهم يعدموغم.

\section{1. أغراض الحطابة الإمام الحميني}

واما أغراض هذه الخطبة هي خطبة السياسية (من الديمقراطية والإقتصادية والثقافة).

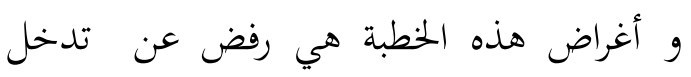
أمريكا فن شؤون الداخلية لإيران.
عليه. تالطبح أغم لايدعون أن يرسل الشعب

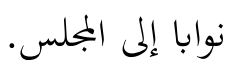

هذا ايضا لأن بلدنا قد تقدم، أي أن

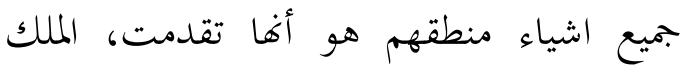
تقدم، اي أن كل ما يملك هذا البلد قد سلموه البداء

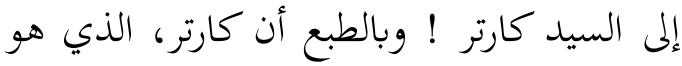
هاب للنفط، يجب أن يقول مثل هذا الشيء.

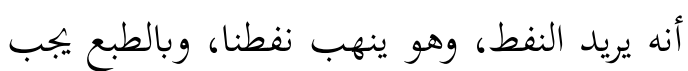
أن يقول مثل هذا الكلام.

ومطلبة الثالث ايضا، بالطبع انكم ان كل من هذه الأشياء يطول الحديث عنها، الاّ أنكم تعملون، مطلبة الثالث أيضا، هو أننا لاننوى التدخل في الشؤون الداخلية لهذا البلد،

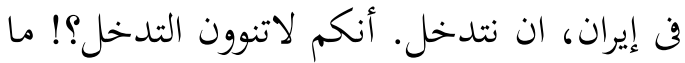
الذي لم تتدخلوا فيه؟ ماذا يعمل مستشاروكم فن جيشنا؟ ولماذا جاء هؤلاء المستشارون؟ ماذا يفعلون ؟ انتم الذين بنيتم القواعد في جبال إيران، من الذي بناها؟ ولمن بنيتموها؟ اليس هذا تدخل في شؤون بلدناب اليس كلامك هذا تدخل؟ ألست أنت الذي ترغب الملك فن أن هلن يُخرب البلاد هكذا الست تتدخل، بأيّ حال من الته الأحوال، في البلد؟ أنه يقول شخصيا أفم كانوا

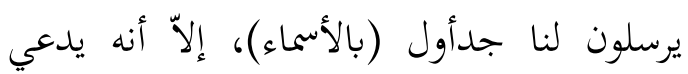
الآن أن كلا أفم لم يعودوا يرسلون الان!أنه يكذب، كلا، أفم يرسلون الآن ايضا. فالأن

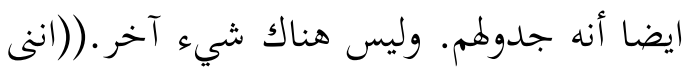

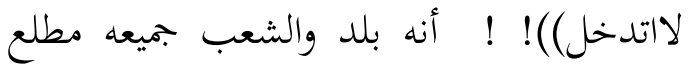


في هذه الخطبة : اذهبوا واسألوا فن أيّ مدينة من مدن إيران أن من يكون هذا الحها النائب من قبلكم يا سيدى؟ من من إيران ان من

ليسألوا من ايّ مدينة من مدن إيران شاءوا؟

حسنا ليأتوا ويقولوا ايّ من هؤلاء النواب في طهران؟

طيب اكتبوا، أن الملك هكذا يفعل؟

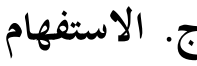

همة : يوجد في خطبة الإمام الخميني

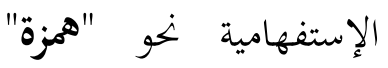
وهذه الممزة تدل على معنى

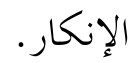

(هزة) مثال : أليس هذا التدخل فن

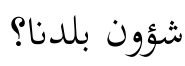

أليس كلامك هذا

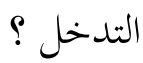

هل: يوجد في خطبة الإمام الخميني

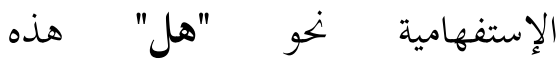

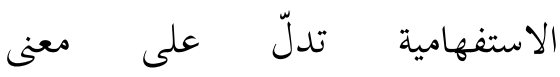
الاستفهامية العامة.

(هل) مثال : هل أن هذه الديمقراطية

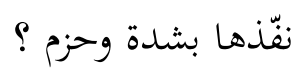

الخطابة السياسية وهدفها اقناع المسلمين برأى سياسى يستحسن الناس به الحكم القائم،

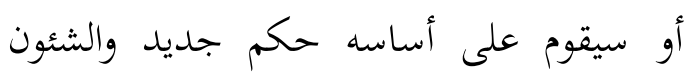
العامة للدولة كفى البرمان المجتمعات الإنتخابية والأندية الحربية والمؤتمرات الدولة سوى تعلقت العمات المئدات الإنخاية

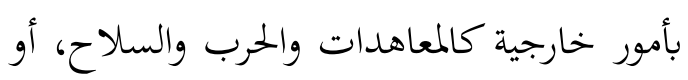

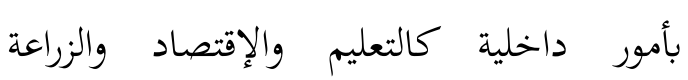
والتشريع ونظم الحكم.

2. عناصر الأسلوب في خطبة الإمام الحميني وجد الباحث الأساليب في خطبة الإمام الخميني منها:

$$
\text { الإنشاء الطلبي }
$$

أ. النداء : يوجد في خطبة الإمام الخميني النداء كقوله " يا سيدى تفيد حرف الند الندام النديني النداء "يا" على النداء البعيد. ب. الأمر: يوجد في خطبة الإمام الخميني

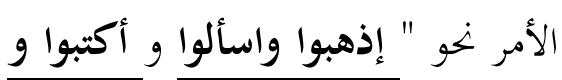
ليسألوا و ليأتوا فصيغة: إذهبوا واسألوا

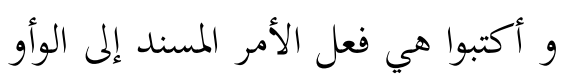

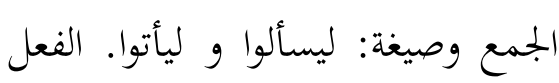

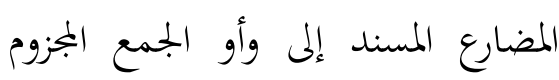

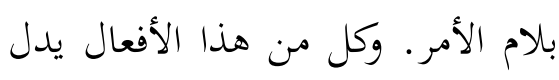

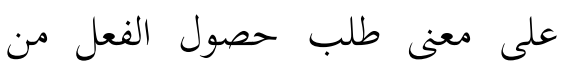
المخاطب على وجه الاستعلاء. 


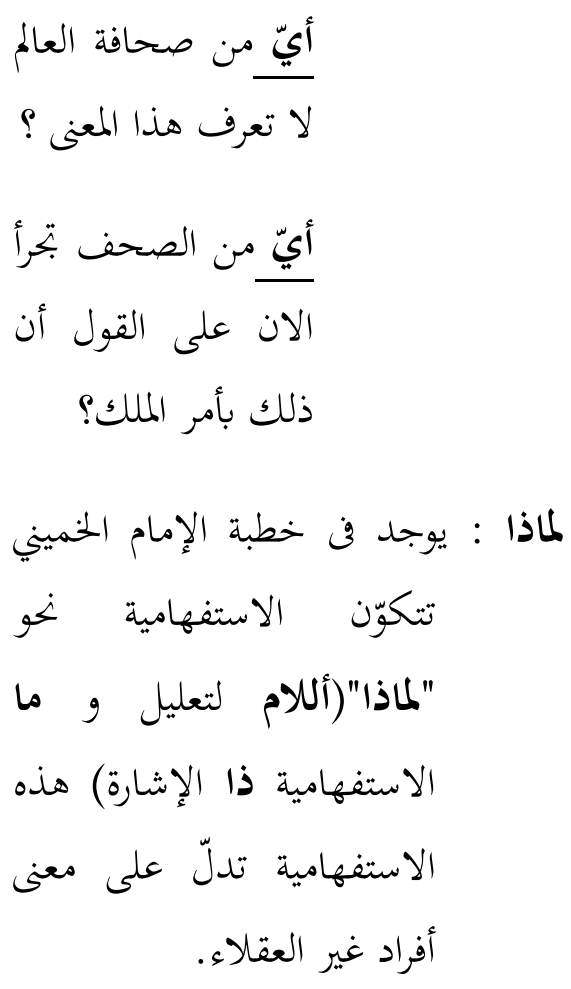

إذهبوا وسألوا فن أيّ

مدينة من مدن إيران

أن من يكون هذا من مدن إيران

النائب من قبلكم يا

$$
\text { سيدى؟ }
$$

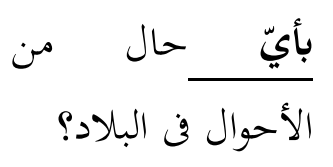

والاستفهامية "أيّ" تدلّ على معنى

$$
\text { هذا بعم أيّ إنسان هو }
$$$$
\text { العدد. }
$$ 
ج. الجمع : يوجد في خطبة الإمام

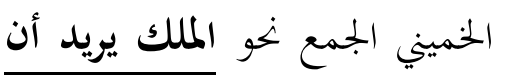

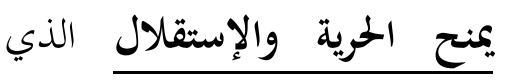
يجمع المتكلم بين متعدد، تحت حكم واحد.

د. الأسلوب الحكيم : يوجدفى خطبة

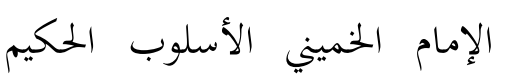

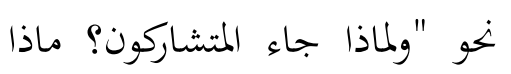
يفعلون؟ انتم الذين بنيتم القواعد في جبال إيران، من الذي بناها؟ الذي تدل على معنى غير ما يترقبه بترك سؤله والإجابة عن السؤال لم يسأله. المحسنات اللفظية هـ الاقتباس : يوجد في خطبة الإمام

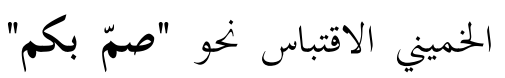

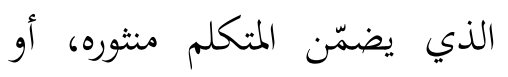
منطومه، شيئا من من القران، أوالحديث، على وجه لابشعر بأنه منهما:فمثاله من (النثر). ومثاله من القرآن : صمّ بكم عمي فهم لا ير جعون (البقرة :18)

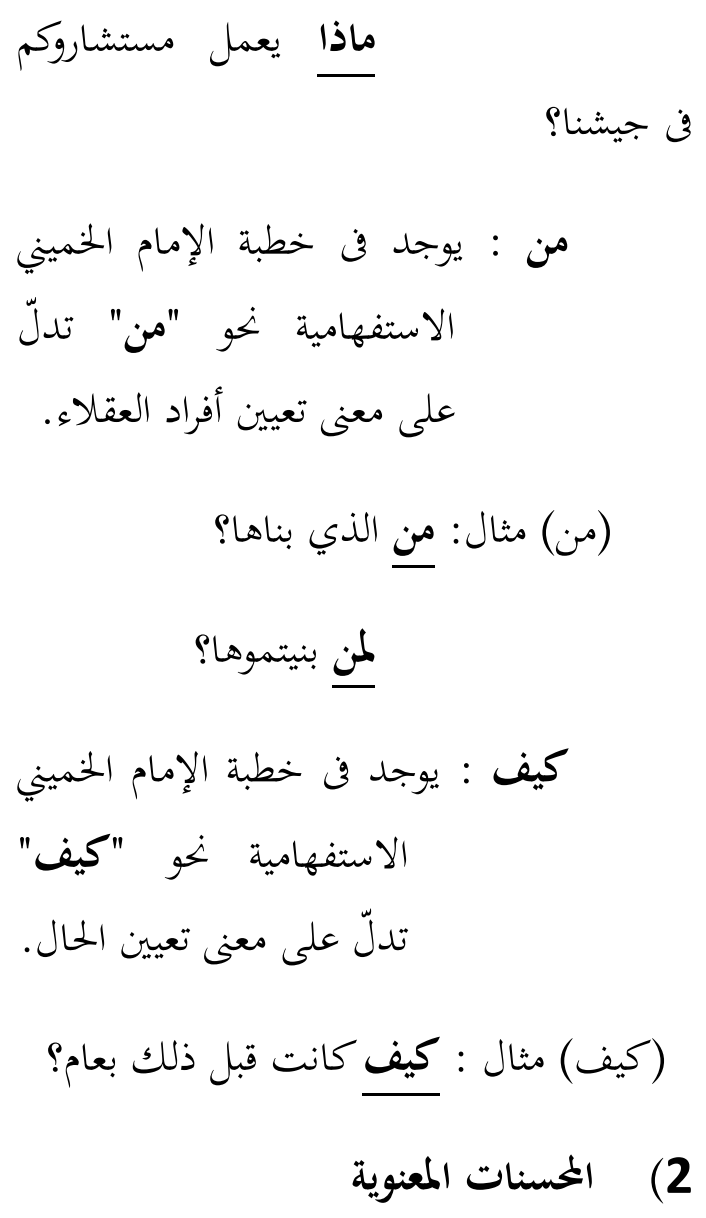

أ. الطباق : يوجد في خطبة الإمام

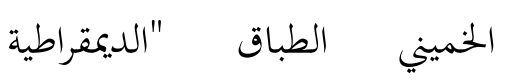

الشديدة. . . أن هذا المعنى أدى المين المعرافية

إلى أن يبدأ اليسار واليمين

معارضتهما" فن اللفظين المقابلين في المعنى.

ب. التفريق : يوجد في خطبة الإمام

الخميني التفريق نخو أننا لا نريد

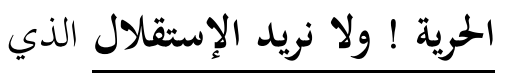

يفرق بين أمرين من نوع واحد في الإنقلال الدي اختلاف حكومها. 
وضمنت العناصر البلاغية التى تتكون من الإنشاء الطلى والمحسنات المعنوية المحسنات اللفظية والخبر.

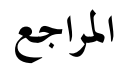

أحمد حسين الزيات. تاريخ الأدب العربي للمدارس الثانوية والعليا. القاهرة : دار

$$
\text { النهضة مصر للطبع والنثر، د. ت. تل }
$$

أحمد محمد. الخوفي، فن الخطابة. القاهرة : دار النهضة، 1997.

أحمد الهاشمي. جواهر البلاغة. بيروت : دارالفكر،

أشرف محمد موسى. الخطابة وفن الإلقاء؟ القاهرة: مكتبة الخنجي، د. ت.

حميد الأنصر. حديث الانطلاق. طهران: مؤسس تنظيم ونشر تراث الإمام الخميني، د. ت.

عبد العزيزبن محمد الفيصل. الأدب العربي

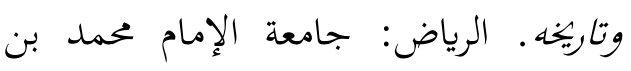
سعود الإسلامية، ب . ع 1.
استخدمه الخطيب خبرا طلبيا في خطبته

كقوله : أن الملك قد أجرى ديمقراطية

شديدة و حازمة في ءيران

الخاتمة

والخطابة هي فن من فنون الكلام، غايته إقناع السامعين، واستمالتهم، والتأثير فيهم، بصواب قضية أو بخطأ أخرى. نشأت الخطابة كفن الادبى قائم بذاته عندما كانت أهم وسيلة للاتصال بالجماهير وتوجيهها، ولذالك اختلطت بلك لهن في نشأتها الأولى عند اليونان القدماء بفنون مختلفة من القول.

وعندما ظهر الإسلام تطورت الخطابة منذ أن الخذها الرسول الله صلى الله عليه وسلم أداة للدعوة إلى الدين طوال حياته. فقد إنتقلت الخطابة مع الزمن من العصر الجاهلى إلى العصر الإسلام ليزيد هذا اللون الأدبي نشاطا. فاستحالت لونا آخر في مبناه ومعناه حيث استجابت الخطابة لدعوة الإسلام و تأثرت بأسلوب القرآن الكريم فن التوجيه والإرشاد واقتبست من حكمه الهاديات وتحلت بآياته المحكمات، كما تأثرت أساليب الخطابة الإسلامية أيضا بجوامع كلمة النبي صلى الله عليه وسلم. وكانت من خطب الخميني الذي بحث فيه الباحث لما أغراض في بجال خطبة السياسية من الديمقراطية و الإقتصادية والثقافة لرفض التدخل الأمريكي في شؤون إيران الداخلية. 
لجنة التحرير. لمحات من حبات وجهاد الإمام

الخحيني. طهران: مؤسس تنظيم ونشر تراث

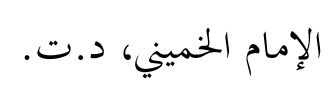

لويس مألوف اليوعى. المنجد في اللغة والاعلام.

بيروت : دار المشرق، 1286.

نبيلة لوبس. المعين في الأدب العربي وتاريخه.

جاكرتا: كلية الأدب والعلوم الإنسانية

جامعة شريف هداية الله، د.ت.
عبد العزيزبن محمد الفيصل. الأدب العربي وتاريخه. المكتبة العربية : وزارة التعليم العإلى اللى لعبدئ

.1405،

عبداللطيف حمزة. الاعلام في صدر الإسلام.

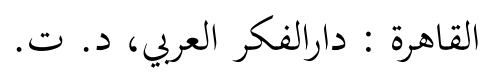

علي محفوظ. الخطابة.المدينة المنورة : المكتبة العلمية، د. ت. 